Document downloaded from:

http://hdl.handle.net/10251/180663

This paper must be cited as:

Llopis-Castelló, D.; Findley, DJ.; García García, A. (2021). Comparison of the highway safety manual predictive method with safety performance functions based on geometric design consistency. Journal of Transportation Safety \& Security. 13(12):1365-1386. https://doi.org/10.1080/19439962.2020.1738612

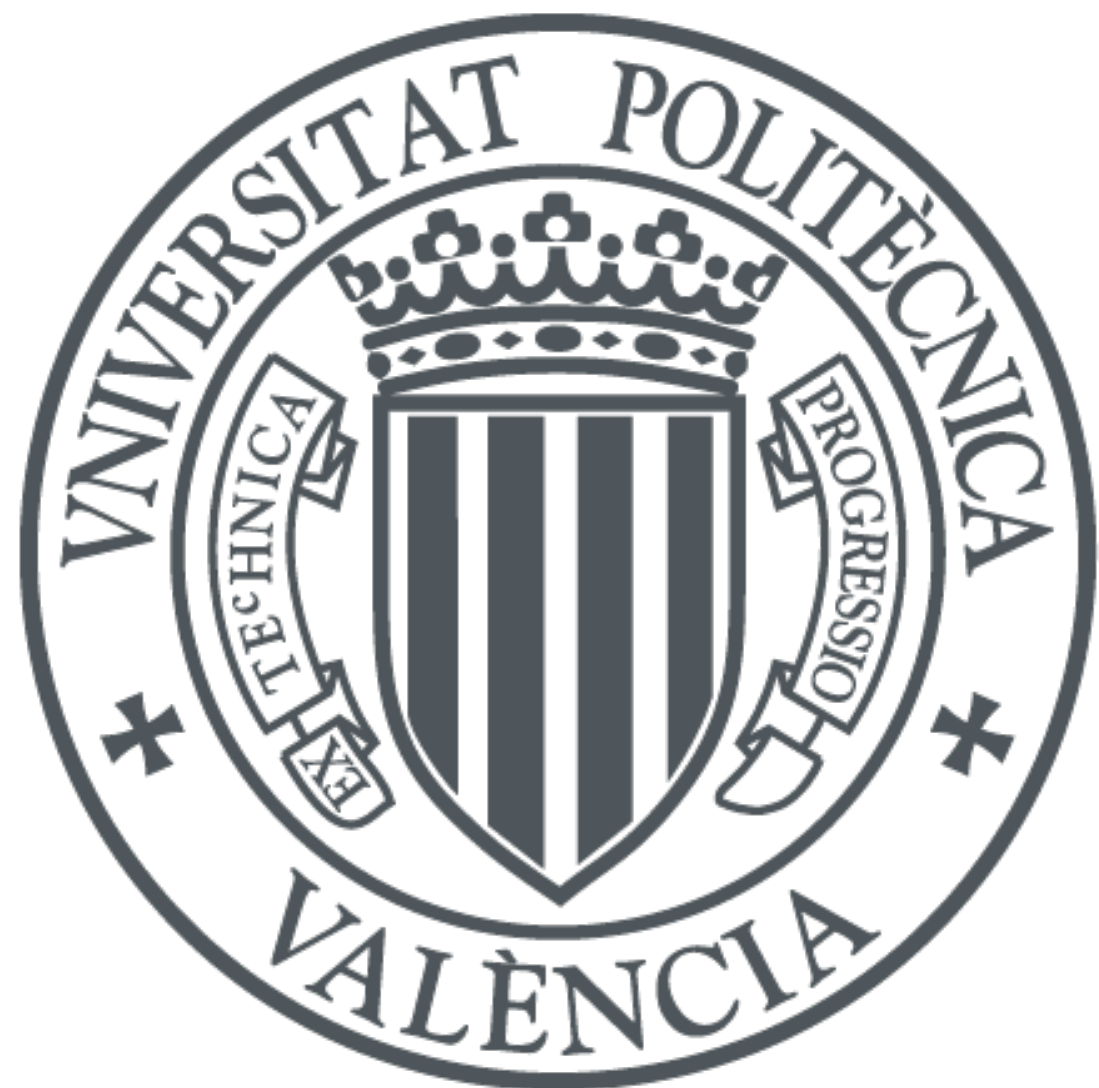

The final publication is available at

https://doi.org/10.1080/19439962.2020.1738612

Copyright Taylor \& Francis

Additional Information

This is an Accepted Manuscript of an article published by Taylor \& Francis in Journal of Transportation Safety \& Security, available online:

http://www.tandfonline.com/10.1080/19439962.2020.1738612 


\section{Comparison of the Highway Safety Manual Predictive Method with Safety Performance Functions Based on Geometric Design Consistency}

3 David Llopis-Castelló, Assistant Professor, (dallocas@upv.es); Highway Engineering Research Group 4 (HERG), Universitat Politècnica de València, Camino de Vera, s/n - 46022, Valencia, Spain; ORCiD: 0000$5 \quad 0002-9228-5407$

6 (Corresponding author)

7 Daniel J. Findley, Ph.D., P.E., Senior Research Associate, (ㅁaniel_Findley@ncsu.edu); Institute for 8 Transportation Research and Education, North Carolina State University, Centennial Campus Box 8601, 9 27695-8601 Raleigh, NC, USA; ORCiD: 0000-0003-4929-8613

10 Alfredo García, Professor, (agarciag@tra.upv.es); Highway Engineering Research Group (HERG), 11 Universitat Politècnica de València, Camino de Vera, s/n - 46022, Valencia, Spain; ORCiD: 0000-0003$12 \quad 1345-3685$

13

14 Word count: 5,794 words

15 Tables: 3

16 Figures: 7 


\section{Abstract}

18 Road safety is a major public health concern in our society. Effective road design and accurate

19 safety analyses must be a component of programs focused on reducing and eliminating roadway

20 injuries and deaths. Various methodologies exist to determine the expected number of crashes on

21 rural two-lane rural roads. This research compares different procedures which allow for the

22 estimation of the number of crashes on homogeneous road segments. In this effort, a total of 27

23 two-lane rural road sections located in North Carolina were considered, resulting in 59

24 homogeneous road segments composed of 350 horizontal curves and 375 tangents along $150 \mathrm{~km}$

25 of road. Four methods were applied to the selected roadways: the HSM predictive method, two 26 jurisdiction-specific Safety Performance Functions (SPFs), and a SPF which includes a

27 consistency parameter.

28 This research found that the use of SPFs which incorporate a consistency parameter allows

29 highway engineers to consider human factor impacts on road safety assessment. The use of a 30 consistency parameter can also simplify the crash estimation process. Analysis methods which 31 only included local geometric variables provided unreliable results due to the calibration of only 32 the specific road elements instead of their relationship with other road elements along 33 homogeneous road segments.

34 Keywords: geometric design consistency, road safety, operating speed, inertial operating speed, 35 driver's behavior 


\section{1. Introduction}

38 Road safety is a public health concern due to the years of productive lives lost resulting from 39 crashes. More than 35,000 people per year die in road crashes in recent years in the United States.

40 Particularly in North Carolina (US), the number of fatal crashes increased by 7\% between 2014

41 and 2015, which was similar to the average increase in the country. In addition, $70 \%$ of fatal 42 crashes occurred on rural highways in this state (FHWA, 2017).

43 In 2010, the American Association of State Highway and Transportation Official (AASHTO) 44 released the Highway Safety Manual (AASHTO, 2010). The HSM is the product of more than 10

45 years of effort and thousands of hours to develop fact-based analytical tools and techniques to 46 quantify the potential safety impacts of planning, design, operations, and maintenance decisions

47 (Xie et al., 2011). Part C of the HSM contains the predictive methods for rural two-lane roads, 48 rural multilane highways, and urban and suburban arterials. The main purpose of the predictive 49 methods is to estimate the average crash frequency for existing conditions, alternatives to existing 50 conditions, or proposed new roadways. The HSM predictive method is based on three components 51 to estimate the predicted number of crashes at a site:

52 (1) Base model, which is a Safety Performance Function (SPF),

53 (2) Crash modification factors (CMFs) to adjust the estimate for site-specific conditions, and

54 (3) A calibration factor (C) to adjust the estimate for local conditions.

55 These components are combined in the following general form:

$$
N_{\text {predicted }}=N_{s p f} \cdot \prod_{i=1}^{n} C M F_{i} \cdot C
$$

$56 \quad N_{\text {predicted: }}$ : predicted average number of crashes for a specific site 
$N_{s p f}$ : predicted number of crashes for base conditions

$C$ : calibration factor

The SPF for rural two-lane, two-way roadway segments is defined as follows:

$$
N_{s p f}=L \cdot A A D T \cdot 365 \cdot 10^{-6} \cdot e^{-0.312}
$$

$N_{s p f:}$ total number of crashes

$A A D T$ : annual average daily traffic volume (vehicles/day)

64 The HSM proposes a total of $12 \mathrm{CMFs}$ for rural two-lane, two-way roadway segments, which are

65 based only on geometric variables and environmental conditions. In addition, the calibration factor

66 (C) is calibrated based on the ratio of the total number of observed crashes and the sum of the

67 predicted number of crashes on all homogeneous segments based on a sample of locations.

68 Therefore, the HSM predictive method does not include a surrogate measure of human factors,

69 which along with infrastructure factors, have been thoroughly studied in recent years through

70 geometric design consistency, which can be defined as how drivers' expectations and road behavior 71 relate.

72 The main objective of geometric design consistency is to minimize the emergence of unexpected

73 events when road users traverse a road segment. Thus, a consistent road provides a harmonious

74 driving experience free of surprises, whereas an inconsistent road might lead to numerous 75 unexpected events to drivers, inciting an anomalous behavior and increasing the likelihood of crash 76 occurrence. 
77 The most common method to assess geometric design consistency is based on the analysis of the

78 operating speed profile (Gibreel et al., 1999; Ng and Sayed, 2004). Operating speed is commonly

79 defined as the $85^{\text {th }}$ percentile of the speed distribution of passenger cars under free-flow conditions

80 and no external restrictions $\left(V_{85}\right)$.

81 There are two types of consistency models: local and global. Local models aim to identify where

82 road crashes are more likely to occur by analyzing localized issues, such as high differences

83 between the design and operating speeds or sudden speed reductions. On the other hand, global

84 consistency models study the overall speed variation along an entire road segment. They do not

85 identify where crashes are more likely to take place, but they can be introduced into a SPF to

86 estimate the number of crashes on an entire road segment.

87 Regarding the usefulness of consistency, several researchers have tried to link the number of 88 crashes to different variables related to risk exposure (traffic volume and road length), geometry,

89 consistency, and road environment by means of SPFs. Among those studies which incorporate

90 consistency as an explanatory variable, all of them concluded that the level of consistency has a

91 major influence on road crash occurrence (Anderson et al., 1999; Ng and Sayed, 2004; Awatta et

92 al., 2006; Montella et al., 2008; Cafiso et al., 2010; de Oña et al., 2013; Quddus, 2013; Wu et al.,

93 2013; Garach et al., 2014; Camacho-Torregrosa, 2015; Montella and Imbriani, 2015; Garach et al., 94 2016).

95 The selection of the road segment is crucial for the application of global consistency models.

96 Selected road segments must be homogeneous, because the results depend on the appropriate

97 selection segments (Resende and Benekohal, 1997; Cafiso et al., 2010; García et al., 2013;

98 Camacho-Torregrosa, 2015). The HSM defines a "site" as "an intersection or a homogeneous 
99 roadway segment". In this regard, for rural two-lane, two-way roadways, a homogeneous road 100 segment is one which keeps constant values for all the Crash Modification Factors and for other 101 parameters such as traffic volume or roadside condition. This means that every road element 102 (tangent and horizontal curve) is usually considered as a homogeneous road segment. Therefore,

103 the HSM predictive method involves the estimation of the number of crashes on an entire road 104 segment as the sum of the number of crashes of all individual road elements along the segment, 105 possibly losing the meaning of the phenomenon being studied and the interaction between 106 successive elements.

107 Driver's behavior is constantly changing along a road segment, so drivers might behave differently 108 in response to the same road element located on different road sections (for instance, a sharp curve 109 located amongst other sharp curves is likely to experience fewer crashes than a curve with the 110 same dimensions located adjacent to long tangents). Road crashes depend not only on local 111 geometric characteristics of a certain road element, but also on the characteristics of the preceding 112 road section. Therefore, road safety evaluation should be carried out considering both local and 113 global road behavior as well as drivers' behavior.

114 Llopis-Castelló et al. (2019b) recently calibrated the following SPF based on consistency to 115 estimate the predicted number of crashes on North Carolina's two-lane rural roads (considering $116665 \mathrm{~km}$ of highway, which resulted in 194 homogeneous road segments):

$$
y=e^{-5.46301} \cdot L^{0.84067} \cdot A A D T^{0.73116} \cdot e^{0.03055 \cdot C}
$$

$117 \quad y$ : number of fatal-and-injury crashes on an entire road segment over 5 years

118 : length of homogeneous road segment $(\mathrm{km})$

$119 C$ : consistency parameter $(\mathrm{km} / \mathrm{h})$ - based on the difference between the inertial operating 
122 To this regard, the risk on horizontal curves is not associated with the specific radius of the curve,

123 but the difference of this curve to the adjacent road elements. For this reason, the inertial operating

124 speed is recommended to be used. This speed aims to represent drivers' expectancies from the 125 speeds experienced before arriving at a certain location on the road.

126 The use of the HSM predictive method has a weakness concerning the influence of risk exposure.

127 The HSM assumes a proportional relationship between risk exposure (traffic volume and road 128 length) and road crashes (Equation 2). Thus, a road segment with $x$ predicted number of crashes 129 will present $2 x$ crashes if its length or traffic volume is doubled. Under this assumption, crash rate 130 remains constant independently of risk exposure. However, many authors have identified that this 131 relationship is not proportional, but crash rates increase or decrease as a function of risk exposure

132 (Montella and Imbriani, 2015; Garach et al., 2016; Llopis-Castelló et al., 2019b; Srinivasan and 133 Carter, 2011; Mehta and Lou, 2013; Srinivasan et al., 2016; Lord et al., 2010; Li et al., 2017). 134 Equation 4 shows the most common functional form of a SPF to estimate the number of crashes 135 on two-lane rural roads:

$$
y=\beta_{0} \cdot L^{\beta_{1}} \cdot A A D T^{\beta_{2}} \cdot e^{\sum_{i=3}^{k} \beta_{i} \cdot x_{i}}
$$

$136 \quad y$ : predicted number of crashes $\beta_{i}:$ regression coefficients

139 The regression coefficient related to $A A D T\left(\beta_{2}\right)$ is usually less than one when considering fataland-injury crashes, meaning that the crash rate decreases as traffic volume of the road segment 
141 increases. However, the influence of the road segment length on crash rate is not as clear as those

142 observed for the traffic volume. Some authors identified that crash rates increase as the length

143 increases $\left(\beta_{1}>1\right)$, whereas other authors observed the opposite effect $\left(\beta_{1}<1\right)$. Despite the

144 uncertainty of the true value of $\beta_{1}, L$ is likely not directly proportional to the number of crashes in

145 many instances. Additionally, some researchers have concerns with the use of baseline models

146 combined with CMFs and a calibration factor for predicting road crashes (Equation 1) because the

147 increase in the variance associated with the final prediction, affecting the reliability of the model

148 (Lord et al., 2010; Shin et al., 2015).

149 Alternatively, the HSM proposes the calibration of jurisdiction-specific SPFs, but does not discuss 150 the use of other variables in developing SPFs. Most studies that have analyzed these two

151 alternatives concluded that jurisdiction-specific SPFs allow highway engineers to more accurately 152 estimate the number of crashes (Srinivasan and Carter, 2011; Mehta and Lou, 2013; Srinivasan et 153 al., 2016; Lord et al., 2010; Li et al., 2017; Brimley et al., 2012; Lu et al., 2014). Therefore, this 154 research aims to compare the application of the HSM predictive method with the use of 155 jurisdiction-specific SPFs based on the HSM guidelines, i.e., on local geometric variables and 156 consistency parameters on North Carolina's two-lane rural roads.

\section{2. Objectives}

158 The main objective of this research was to evaluate the applicability and efficacy of using 159 jurisdiction-specific Safety Performance Functions instead of the HSM predictive method in the 160 estimation of the number of crashes on rural two-lane, two-way roadway segments. This 161 comparison was carried out considering two types of jurisdiction-specific SPFs calibrated in North 162 Carolina: (i) those developed by Srinivasan and Carter (2011) and Smith et al. (2017), which were 163 calibrated considering the HSM guidelines, i.e., only considering geometric and/or environmental 
164 variables; and (ii) that proposed by Llopis-Castelló et al. (2019b) which supplements the HSM

165 recommendations with the concept of geometric design consistency.

166 The underlying hypothesis is that a SPF based on a consistency parameter provides a more reliable

167 estimation of the number of crashes than the HSM predictive method and those SPFs based only

168 on geometric variables, since the consistency parameter includes the interaction between the

169 infrastructure and human factors, which plays an essential role for road safety.

\section{3. Methodology and Data Description}

\section{3.1. Methodology}

172 This research was focused on the analysis of the HSM predictive method and its comparison with

173 jurisdiction-specific SPFs calibrated in North Carolina (Figure 1). A total of 27 two-lane rural road

174 sections located along NC-96, NC-42, and NC-268 roadways were selected. The horizontal

175 alignment for each road section was recreated by means of the procedure developed by Camacho-

176 Torregrosa et al. (2015), while the cross-section of each road element was determined through

177 aerial images. Crash and traffic data were also obtained. The number of predicted crashes was

178 estimated considering the HSM predictive method as well as using the jurisdiction-specific SPFs.

179 Finally, the relationship between the observed and predicted crashes for each procedure was

180 studied considering the following parameters of goodness of fit: Mean Absolute Deviation $(M A D)$,

181 Root Mean Square Error (RMSE), and Cumulative Residuals (CURE) plots.

\section{3.2. Road segments}

183 A total of 27 two-lane rural road sections located in North Carolina with no geometric changes in

184 the time period selected for crash data were selected for the study. This required the geometric 185 recreation of approximately $150 \mathrm{~km}$ (90 miles) of highway covering 350 horizontal curves and 375 
tangents. Therefore, 725 homogeneous road segments were obtained according to the HSM, since

187 this selection depended on the CMFs.

188 Length, radius, and the presence or absence of spiral transition were identified from this geometric 189 recreation. Lane width, shoulder width and type, number of driveways, and roadside design were

190 obtained from aerial images for each road element (Table 1). These road sections are located in the 191 Piedmont of North Carolina and are assumed to have a grade flatter than $3 \%$ (level grade) and do 192 not contain centerline rumble strips, passing lanes, lighting, or automated speed enforcement 193 (Figure 2). A superelevation rate that was adequate according to the AASHTO design guide was 194 assumed for each horizontal curve.

195 The identification of homogeneous road segments was needed to apply the jurisdiction-specific 196 SPF based on the global consistency model proposed by Llopis-Castelló et al. (2018), which was 197 based on the following method. First, road sections were divided into segments with similar cross198 section and traffic volume (Figure 2b). Major intersections also influence drivers' behavior, so they 199 were also taken into account for segmentation. Finally, each road segment was divided considering 200 its geometric behavior using the German methodology, which is based on the analysis of the 201 Curvature Change Rate $(C C R)$. This parameter is defined as the sum of the absolute deflection 202 angles divided by the length of the road segment. Figure 2c represents how this last step is 203 conducted: a profile of the cumulative absolute deflection angle versus the road station must be 204 plotted. In this way, homogeneous road segments can be distinguished according to similar $C C R$ 205 behavior. As a result, 59 homogeneous road segments were identified (Table 1).

\subsection{Traffic and crash data}

207 Traffic volume and crash data were provided by the North Carolina Department of Transportation 
208 (NCDOT). AADT and the number of reported crashes were identified for each homogeneous road 209 segment between 2012 and 2016.

210 In North Carolina, a crash must only be reported if there are injuries or if the property damage is

211 equal to or greater than $\$ 1,000$. Therefore, Property Damage Only (PDO) crashes are not always

212 reported to authorities and, consequently, to include this type of crash might lead to biased results 213 and an inaccurate interpretation of the phenomenon under investigation (Xie et al., 2011; Shin et 214 al., 2015). Thus, only reported fatal-and-injury crashes were considered over this study period. As 215 a result, a total of 223 reported crashes were analyzed, 130 of which occurred on horizontal curves 216 and 93 on tangents. For the application of the HSM predictive method, the percentage of fatal-and217 injury crashes $\left(p_{i}\right)$ and the proportion of related crashes $\left(p_{r a}\right)$, which is estimated as the percentage 218 represented by ran off road crashes, head-on collisions, and sideswipe collisions, are required. 219 North Carolina values for this study included $p_{i}$ of $33.4 \%$ and $p_{r a}$ of $39.1 \%$ (Llopis-Castelló et al., 220 2019a). In this way, the number of fatal-and-injury crashes was estimated by multiplying the 221 predicted total number of crashes by 0.334 .

\section{3.4. Crash Modification Factors and Calibration Factors}

223 The CMFs proposed by the HSM to estimate the number of predicted crashes on rural two-lane, 224 two-way roadway segments were calculated according to Chapter 10 of the HSM. Table 2 shows 225 a statistical summary of these factors.

226 The calibration factor attempts to adjust the predicted number of crashes for local conditions.

227 Specifically, the calibration factors used in this research are those proposed by Llopis-Castelló et 228 al. (2019a), which were developed in North Carolina considering only fatal-and-injury crashes: 2291.57 for horizontal curves and 1.15 for tangents. These are preferred instead of a global calibration 
230 factor for both tangents and horizontal curves because they result in a more accurate estimation of

231 the number of crashes.

\section{$232 \quad 3.5 . \quad J u r i s d i c t i o n-s p e c i f i c$ SPFs}

233 The HSM predictive method will be compared with the state-specific SPFs developed by

234 Srinivasan and Carter (2011), Smith et al. (2017), and Llopis-Castelló et al. (2019b). Regarding 235 this, it should be highlighted that all these models were calibrated in the same region of North 236 Carolina.

237 Srinivasan and Carter (2011) proposed two types of state-specific SPFs (Equation 5 and 6). Type 2381 only depends on risk exposure, whereas Type 2 includes different variables related to the cross239 section.

Type 1: $\quad y=e^{-5.2717} \cdot L \cdot A A D T^{0.6071} \cdot C_{\text {annual }}$

Type 2: $\quad y=L \cdot e^{\left(0.1221+0.4924 \cdot \ln \left(\frac{A A D T}{10,000}\right)+0.3723 \cdot \frac{A A D T}{10,000}-0.0244 \cdot S W+0.0479 \cdot S T\right)}$

$240 \quad C_{\text {annual: }}$ annual factor

$241 \quad S W:$ shoulder width (feet)

$242 S T$ : shoulder type (1 for unpaved and 0 for paved)

243 Smith et al. (2017) generated different calibration functions for the three different regions in North

244 Carolina: Coast, Mountain, and Piedmont (Equation 7, 8, and 9). These SPFs depend on the same 245 variables proposed by the HSM predictive method.

$$
\begin{aligned}
& \text { Coast: } \quad y=0.965 \cdot e^{-3.1953} \cdot L \cdot A A D T^{0.6496} \cdot \prod_{i=1}^{12} C M F_{i} \\
& \text { Mountain: } \quad y=1.02 \cdot e^{-0.1832} \cdot\left(H_{S M}\right)^{0.8512}
\end{aligned}
$$


Piedmont: $\quad y=0.92 \cdot e^{-5.0530} \cdot L \cdot A A D T^{0.8546} \cdot \prod_{i=1}^{12} C M F_{i}$

248 Therefore, these state-specific SPFs estimate the predicted number of crashes based on 249 infrastructure factors. However, Llopis-Castelló et al. (2019b) developed new SPFs based on 250 geometric design consistency (Equation 3). In this regard, the predicted number of crashes is 251 calculated taking into account the interaction between infrastructure and human factors.

252 The global consistency parameter proposed by Llopis-Castelló et al. (2019b) is calculated from 253 the difference between the inertial operating speed profile $\left(V_{i}\right)$, which represents drivers' 254 expectancies, and the operating speed profile $\left(V_{85}\right)$, which represents road behavior (Figure 4a). 255 This parameter is defined as follows:

$$
C=\sqrt{\frac{A(+) \cdot \sigma(+)}{L(+)}}[\mathrm{km} / \mathrm{h}]
$$
the positive differences $(\mathrm{m} \cdot \mathrm{km} / \mathrm{h})$ (m)

262 Only positive differences were included to focus on locations were the inertial operating speed $\left(V_{i}\right)$ 263 exceeds the operating speed $\left(V_{85}\right)$ because in these sections the likelihood of crash occurrence 
264 increases due to drivers expect to reach higher speeds than those that the road geometry allows 265 them (Figure 4b).

266 Thus, to apply the SPF calibrated by Llopis-Castelló et al. (2019b), the operating speed profile for

267 each road segment was estimated using the speed model for horizontal curves calibrated by Ottesen

268 and Krammes (2000), the speed model for tangents developed by Polus et al. (2000), and the

269 acceleration and deceleration rates proposed by the Interactive Highway Safety Design Model

270 (Figure 4a). Each of these models were calibrated based on speed data collected on American two-

271 lane rural roads. The primary reason for using these models is that the highways considered in this

272 study have similar characteristics to those used in the calibration of these models regarding 273 geometric features, road functionality, and traffic conditions.

274 The inertial operating speed profile was calculated for every road segment based on its operating 275 speed profile for both forward and backward direction (Figure 4a). According to Llopis-Castelló 276 et al. (2018), the inertial operating speed is defined for each point of the alignment as the weighted 277 average operating speed of the preceding 15 seconds considering a linear weighting distribution:

$$
V_{i, k}=\frac{\sum w_{j} \cdot V_{85, j}}{\sum w_{j}}
$$

$278 \quad V_{i, k}$ : inertial operating speed $(\mathrm{km} / \mathrm{h})$ at point $k$

$279 \quad V_{85, j}$ : operating speed at point $j$

$280 w_{j}$ : weighting factor at point $j$ (ranges linearly from 0 for the furthest point to 1 for the $281 \quad$ closest one - carried out for time intervals $(j)$ of $0.1 \mathrm{~s})$

\section{4. Results}

283 The analysis of this study was focused on the comparison of the defined methods to estimate the 
284 number of predicted crashes on entire road segments. Regarding the application of the HSM 285 predicted method and those jurisdiction-specific SPFs proposed by Srinivasan and Carter (2011) 286 and Smith et al. (2017), the predicted number of crashes on a certain homogeneous road segment 287 was calculated as the sum of the predicted number of crashes for all road elements (tangents and 288 horizontal curves) along that segment. The SPF calibrated by Llopis-Castelló et al. (2019b) can 289 directly estimate the number of fatal-and-injury crashes on an entire road segment.

290 This comparison was carried out considering the following parameters of goodness of fit, 291 which aim to assess how predicted and observed crashes fit:

292

- Mean Absolute Deviation (MAD):

$M A D=\frac{1}{n} \sum_{i=1}^{n}\left|\widehat{y}_{l}-y_{i}\right|$

- $\quad$ Root Mean Square Error (RMSE):

$R M S E=\sqrt{\frac{1}{n} \sum_{i=1}^{n}\left|\widehat{y}_{l}-y_{i}\right|^{2}}$

294 - Cumulative Residuals (CURE) Plots: This method consists of plotting the cumulative 295 residuals for each independent variable to graphically observe how well the function fits 296 the data set. The CURE method has the advantage of not being dependent on the number 297 of observations, as are many other traditional statistical procedures. In general, a good 298 cumulative residuals plot is one that oscillates around 0 and where the residuals do not stray beyond the $\pm 2 \sigma^{*}$ boundaries. The residuals are calculated as the difference between the observed and predicted number of crashes and are ordered from lowest to highest value. 
$\sigma^{*}=\sqrt{\sigma_{i}^{2} \cdot\left(1-\frac{\sigma_{i}^{2}}{\sigma_{T}^{2}}\right)}$

$\sigma^{*}:$ limit of the cumulative residuals

$\sigma_{i}^{2}$ : variance of the cumulative residuals until the element $i$

$\sigma_{T}^{2}$ : total variance of the cumulative residuals.

304 Table 3 shows these parameters of goodness of fit and the relationship between the predicted and

305 observed fatal-and-injury crashes for each procedure considering the 59 homogeneous road 306 segments.

307 Overall, all methods performed relatively similarly with respect to the $M A D$ and $R M S E$

308 evaluations. However, the CURE plots provide useful information about the differences and

309 potential shortcomings of each method. Although the use of the SPF proposed by Smith et al.

310 (2017) resulted in the best values of $M A D$ and $R M S E$, this procedure showed a poor performance

311 regarding the CURE plots. The SPFs calibrated by Srinivasan and Carter (2011) provided the worst

312 parameters of goodness of fit and showed a large percentage of points out of the limits of the 313 CURE plots.

314 The HSM predictive method provided an appropriate estimation of the number of fatal-and-injury

315 crashes, but the SPF calibrated by Llopis-Castelló et al. (2019b), which is based on risk exposure

316 and a consistency parameter, resulted in the most accurate results.

317 The CURE plots obtained for each procedure can help explain the study's conclusions (Figure 5

318 and Table 3). In this regard, both SPFs developed by Srinivasan and Carter (2011) overestimate 319 the predicted number of fatal-and-injury crashes. In addition, the SPF calibrated by Smith et al. 320 (2017) underestimated the number of fatal-and-injury crashes. Specifically, this procedure showed 
321 an inaccurate performance relative to the length of the road segment. This can be explained by the

322 functional form of the SPF. This considers a regression coefficient equal to 1 for the $L$. However,

323 the relationship between the length of the road segment and crash rate is not directly proportional.

324 Overall, the SPF proposed by Llopis-Castelló et al. (2019b) showed the most accurate CURE plots

325 because this resulted in the lowest percentage of points out of the limits $(11.86 \%$ and $10.17 \%$

326 considering $A A D T$ and $L$, respectively). Therefore, this SPF provides a more reliable estimation of

327 the number of fatal-and-injury crashes and, consequently, a better road safety assessment.

\section{5. Discussion}

329 Multiple jurisdiction-specific SPFs have been compared to the HSM predictive method. Among

330 these SPFs, that proposed by Llopis-Castelló et al. (2019b) showed a more accurate estimation of

331 the number of fatal-and-injury crashes. Specifically, this SPF is based on risk exposure and adds a

332 parameter $C$ that represents geometric design consistency.

333 The consistency parameter $C$ can be estimated by applying operating speed models. Therefore,

334 this SPF does not require a field data collection as the application of the HSM predictive method

335 and the use of the SPFs developed by Srinivasan and Carter (2011) and Smith et al. (2017)

336 suggests, which can be a substantial advantage. In addition, the consistency parameter $C$ proposed

337 by Llopis-Castelló et al. (2019b) considers the interaction between infrastructure and human

338 behavior, which is considered the primary causal factor for crash occurrence.

339 Furthermore, these results reveal the crucial role of the identification of the homogeneous road

340 segments. The HSM predictive method and the SPFs proposed by Srinivasan and Carter (2011)

341 and Smith et al. (2017) were calibrated based on road elements instead of homogeneous road

342 segments. However, from a drivers' point of view, the likelihood of crash occurrence on a certain 
343 road element does not only depend on its local characteristics, but also on the global geometric

344 behavior. This finding reinforces previous work by Findley et al. (2012) which quantified the 345 importance of the influence of adjacent roadway elements. Therefore, the fact that the SPF 346 proposed by Llopis-Castelló et al. (2019b) was calibrated for the assessment of road safety on an 347 entire homogeneous road segment might explain why this model provided more reliable results.

348 To more closely examine the source of resulting analytical differences, a disaggregated analysis 349 was developed to study the strength of the SPFs developed by Srinivasan and Carter (2011) and 350 Smith et al. (2017). This analysis was based on the comparison between the observed and predicted 351 number of fatal-and-injury crashes on individual road elements: horizontal curves and tangents. 352 Figure 6 and Figure 7 show the CURE plots obtained for these SPFs considering both the traffic 353 volume and the length of each horizontal curve and tangent, respectively.

354 Although the SPFs calibrated by Srinivasan and Carter (2011) resulted in a reasonable estimation 355 of the number of fatal-and-injury crashes on horizontal curves (Figure 6a and 6b), these SPFs 356 provided a large overestimation of the number of crashes on tangents (Figure $7 \mathrm{a}$ and $7 \mathrm{~b}$ ). The 357 overestimation of crashes on tangents generally results in a broader overestimation of the number 358 of crashes on an entire homogeneous road segment. Conversely, although the SPFs proposed by 359 Smith et al. (2017) resulted in an accurate estimation of the predicted number of fatal-and-injury 360 crashes on an entire homogeneous road segment, the disaggregated analysis showed that these 361 models are not reliable at individual road elements. The number of crashes on horizontal curves 362 was underestimated (Figure 6c), whereas the number of crashes on tangents was overestimated 363 (Figure 7c). Therefore, this SPF may not provide results that are reliable enough to be applied to 364 assess road safety. 
365 Therefore, the calibration of SPFs based on consistency has two important strengths concerning

366 the application of the HSM predictive method and jurisdiction-specific SPF based on local

367 geometric conditions: (i) SPFs based on consistency include the interaction between the

368 infrastructure and human factors, so they better represent the studied phenomenon and provide a

369 more accurate assessment of road safety; and (ii) SPFs based on consistency do not necessarily

370 require field data collection, so their application is easier and more practical for highway engineers,

371 particularly in financially and resource-constrained environments.

\section{6. Conclusions and further research}

373 This research analyzes different procedures to estimate the number of fatal-and-injury crashes on

374 entire homogeneous road segments in North Carolina. Specifically, the predicted number of

375 crashes was calculated considering the HSM predictive method, the jurisdiction-specific SPFs

376 proposed by Srinivasan and Carter (2011) and Smith et al. (2017), and the SPF based on

377 consistency calibrated by Llopis-Castelló et al. (2019b).

378 The strength of these procedures was assessed comparing the predicted number of fatal-and-injury 379 crashes with the reported crashes between 2012 and 2016 through the following parameters of 380 goodness of fit: (i) Mean Absolute Deviarion (MAD); (ii) Root Mean Square Error (RMSE); (iii) 381 Cumulative Residuals (CURE) plots.

382 The results of this study found that the SPFs proposed by Srinivasan and Carter (2011) 383 overestimated the number of fatal-and-injury crashes, whereas the SPFs calibrated by Smith et al. 384 (2017) provided a reasonable aggregate estimation of the number of crashes for an entire road 385 segment, but underestimated the number of crashes on horizontal curves and overestimated the 386 number of crashes on tangents. These limitations are primarily due to the functional form of these 387 SPFs. The influence of risk exposure on crash rate is different for homogeneous road segments, 
388 horizontal curves, and tangents. The number of crashes is not directly proportional to road segment

389 length or traffic volume as the HSM predictive method assumes. This supports the need to calibrate 390 different models depending on the type of road element.

391 Although the application of the HSM predictive method based on calibration factors for each type

392 of road segment (tangents and horizontal curves) provided an appropriate estimation of the number

393 of fatal-and-injury crashes, the SPF calibrated by Llopis-Castelló et al. (2019b), which is based on

394 risk exposure and a consistency parameter, resulted in the most accurate results.

395 In addition, the use of SPFs based on consistency has important advantages concerning the use of

396 the HSM predictive method and jurisdiction-specific SPFs based on local geometric conditions.

397 The first one is that a SPF based on consistency includes the interaction between drivers' 398 expectancies and road behavior, which is the most important factor for crash occurrence. The 399 second is that the application of this type of SPFs does not require a field data collection. This 400 procedure can be applied using operating speed models which is a practical and simple 401 improvement relative to other methods with respect to the assessment of road safety for highway 402 engineers. Likewise, these SPFs are usually calibrated considering homogeneous road segment, 403 i.e., they better represent the phenomenon studied, since the likelihood of crash occurrence at a 404 certain road element do not only depend on the features of this road element, but also on the global 405 conditions.

406 Therefore, the use of SPFs based on consistency allow practitioners and highway engineers to 407 incorporate human factor on road safety assessment as well as an easier and more practical 408 estimation of the number of fatal-and-injury crashes.

409 As this study is mainly focused on the estimation of fatal-and-injury crashes, further research is 
needed to extend the obtained findings to other crash types and severities. Additionally, a temporal

411 analysis considering more years of crash data is proposed to be done so as to strengthen the results

412 of this research. This analysis will be focused on the study of the variability of crash estimation

413 considering different time windows.

\section{Acknowledgments}

415 This research was subsidized by the Spanish Ministry of Science, Innovation, and Universities

416 through "Ayudas a la movilidad predoctoral para la realización de estancias breves en centros de

417 I+D 2017" (EEBB-I-17-12154) and is part of the research project titled "CASEFU - Estudio

418 experimental de la funcionalidad y seguridad de las carreteras convencionales" (TRA2013-42578-

419 P), subsidized by the above mentioned Spanish Ministry and the European Social Fund. In

420 addition, the authors would like to thank the North Carolina Department of Transportation

421 (NCDOT), which provided traffic and crash data.

422

423

424

425

426

427

428

429

430

431

432

433

434

435

436

437

438

439

440

441

442

\section{References}

1. American Association of State Highway and Transportation Official (2010). Highway Safety Manual. Washington, DC.

2. Anderson, I. B., Bauer, K. M., Harwood, D. W., \& Fitzpatrick, K. (1999). Relationship to safety of geometric design consistency measures for rural two-lane highways. Transportation research record, 1658(1), 43-51.

3. Awatta, M., Hassan, Y., \& Sayed, T. (2006). Quantitative evaluation of highway safety performance based on design consistency. Advances in transportation studies, 9.

4. Brimley, B. K., Saito, M., \& Schultz, G. G. (2012). Calibration of Highway Safety Manual safety performance function: development of new models for rural two-lane twoway highways. Transportation research record, 2279(1), 82-89.

5. Cafiso, S., Di Graziano, A., Di Silvestro, G., La Cava, G., \& Persaud, B. (2010). Development of comprehensive accident models for two-lane rural highways using exposure, geometry, consistency and context variables. Accident Analysis \& Prevention, 42(4), 1072-1079.

6. Camacho Torregrosa, F. J. (2015). Development and calibration of a global geometric design consistency model for two-lane rural highways, based on the use of continuous operating speed profiles. Universitat Politècnica de València, Valencia (Spain).

7. Camacho-Torregrosa, F. J., Pérez-Zuriaga, A. M., Campoy-Ungría, J. M., García, A., \& Tarko, A. P. (2015). Use of heading direction for recreating the horizontal alignment of an existing road. Computer-Aided Civil and Infrastructure Engineering, 30(4), 282-299. 
443

444

445

446

447

448

449

450

451

452

453

454

455

456

457

458

459

460

461

462

463

464

465

466

467

468

469

470

471

472

473

474

475

476

477

478

479

480

481

482

483

484

485

486

487

8. de Oña, J., Garach, L., Calvo, F., \& García-Muñoz, T. (2013). Relationship between predicted speed reduction on horizontal curves and safety on two-lane rural roads in Spain. Journal of transportation engineering, 140(3), 04013015.

9. Federal Highway Association (FHWA), 2017. https://safety.fhwa.dot.gov/facts_stats/

10. Findley, D. J., Hummer, J. E., Rasdorf, W., Zegeer, C. V., \& Fowler, T. J. (2012). Modeling the impact of spatial relationships on horizontal curve safety. Accident Analysis \& Prevention, 45, 296-304.

11. Garach, L., Calvo, F., Pasadas, M., \& de Oña, J. (2014). Proposal of a new global model of consistency: Application in two-lane rural highways in Spain. Journal of Transportation Engineering, 140(8), 04014030.

12. Garach, L., de Oña, J., López, G., \& Baena, L. (2016). Development of safety performance functions for Spanish two-lane rural highways on flat terrain. Accident Analysis \& Prevention, 95, 250-265.

13. Garcia, A., Llopis-Castello, D., Perez-Zuriaga, A. M., \& Camacho-Torregrosa, F. J. (2013). Homogeneous road segment identification based on inertial operating speed (No. 13-3545).

14. Gibreel, G. M., S. M. Easa, Y. Hassan, and I. A. El-Dimeery. State of the art of highway geometric design consistency. Journal of Transportation Engineering, 1999, vol. 125, no 4, p. 305-313.

15. Li, L., Gayah, V. V., \& Donnell, E. T. (2017). Development of regionalized SPFs for twolane rural roads in Pennsylvania. Accident Analysis \& Prevention, 108, 343-353.

16. Llopis-Castelló, D., \& Findley, D. J. (2019a). Influence of Calibration Factors on Crash Prediction on Rural Two-Lane Two-Way Roadway Segments. Journal of Transportation Engineering, Part A: Systems, 145(6), 04019024.

17. Llopis-Castelló, D., Findley, D. J., Camacho-Torregrosa, F. J., \& García, A. (2019b). Calibration of inertial consistency models on North Carolina two-lane rural roads. Accident Analysis \& Prevention, 127, 236-245.

18. Llopis-Castelló, D., Camacho-Torregrosa, F. J., \& García, A. (2018). Development of a global inertial consistency model to assess road safety on Spanish two-lane rural roads. Accident Analysis \& Prevention, 119, 138-148.

19. Lord, D., Kuo, P. F., \& Geedipally, S. R. (2010). Comparison of application of product of baseline models and accident-modification factors and models with covariates: Predicted mean values and variance. Transportation Research Record, 2147(1), 113-122.

20. Lu, J., Haleem, K., Alluri, P., Gan, A., \& Liu, K. (2014). Developing local safety performance functions versus calculating calibration factors for SafetyAnalyst applications: A Florida case study. Safety science, 65, 93-105.

21. Mehta, G., \& Lou, Y. (2013). Calibration and development of safety performance functions for Alabama: Two-lane, two-way rural roads and four-lane divided highways. Transportation research record, 2398(1), 75-82.

22. Montella, A., \& Imbriani, L. L. (2015). Safety performance functions incorporating design consistency variables. Accident Analysis \& Prevention, 74, 133-144.

23. Montella, A., Colantuoni, L., \& Lamberti, R. (2008). Crash prediction models for rural motorways. Transportation Research Record, 2083(1), 180-189.

24. Ng, J. C., \& Sayed, T. (2004). Effect of geometric design consistency on road safety. Canadian Journal of Civil Engineering, 31(2), 218-227. 
25. Ottesen, J. L., \& Krammes, R. A. (2000). Speed-profile model for a design-consistency evaluation procedure in the United States. Transportation Research Record, 1701(1), 7685.

26. Polus, A., Fitzpatrick, K., \& Fambro, D. B. (2000). Predicting operating speeds on tangent sections of two-lane rural highways. Transportation Research Record, 1737(1), 50-57.

27. Quddus, M. (2013). Exploring the relationship between average speed, speed variation, and accident rates using spatial statistical models and GIS. Journal of Transportation Safety \& Security, 5(1), 27-45.

28. Resende, P., and R. Benekohal (1997). Effect of roadway section length on accident modeling traffic congestion and traffic safety. The 21 st Century Conference, ASCE, Chicago, IL.

29. Saleem, T., \& Persaud, B. (2017). Another look at the safety effects of horizontal curvature on rural two-lane highways. Accident Analysis \& Prevention, 106, 149-159.

30. Shin, H. S., Dadvar, S., \& Lee, Y. J. (2015). Results and lessons from local calibration process of the highway safety manual for the state of Maryland. Transportation Research Record, 2515(1), 104-114.

31. Smith, S., D. Carter, and R. Srinivasan (2011). Updated and Regional Calibration Factors for Highway Safety Manual Crash Prediction Models. FHWA/NC/2016-09, 2017.

32. Srinivasan, R., and D. Carter. Development of Safety Performance Functions for North Carolina. FHWA/NC/2010-09.

33. Srinivasan, R., Colety, M., Bahar, G., Crowther, B., \& Farmen, M. (2016). Estimation of calibration functions for predicting crashes on rural two-lane roads in Arizona. Transportation research record, 2583(1), 17-24.

34. Wu, K. F., Donnell, E. T., Himes, S. C., \& Sasidharan, L. (2013). Exploring the association between traffic safety and geometric design consistency based on vehicle speed metrics. Journal of transportation engineering, 139(7), 738-748.

35. Xie, F., Gladhill, K., Dixon, K. K., \& Monsere, C. M. (2011). Calibration of highway safety manual predictive models for Oregon state highways. Transportation research record, 224l(1), 19-28. 
517 Table 1. Features of the homogeneous road segments.

\begin{tabular}{|c|c|c|c|c|c|c|c|c|c|c|}
\hline \multicolumn{11}{|l|}{ (a) HSM } \\
\hline \multirow[b]{2}{*}{ Road feature } & \multicolumn{5}{|c|}{ Horizontal curves } & \multicolumn{5}{|c|}{ Tangents } \\
\hline & Min. & Max. & Mean & Median & St. Dev. & Min. & Max. & Mean & Median & $\begin{array}{c}\text { St. } \\
\text { Dev. }\end{array}$ \\
\hline Radius (m) & 37.17 & $9,787.37$ & 833.46 & 412.68 & $1,371.58$ & na & na & na & na & na \\
\hline $\begin{array}{l}\text { Lane width } \\
\text { (m) }\end{array}$ & 2.44 & 3.66 & 3.03 & 3.05 & 0.32 & 2.44 & 3.66 & 3.04 & 3.05 & 0.32 \\
\hline $\begin{array}{l}\text { Shoulder } \\
\text { width }(\mathrm{m})\end{array}$ & 2.44 & 3.66 & 3.03 & 3.05 & 0.32 & 0.61 & 1.83 & 0.96 & 0.91 & 0.38 \\
\hline $\begin{array}{l}\text { Roadside } \\
\text { Hazard Rating }\end{array}$ & 2 & 6 & 3.106 & 3 & 1.210 & 3 & 5 & 3.795 & 3 & 0.975 \\
\hline $\begin{array}{l}\text { DD } \\
\text { (driveways per } \\
\mathrm{km} \text { ) }\end{array}$ & 0.00 & 39.33 & 6.96 & 5.59 & 7.39 & 0.00 & 115.4 & 11.31 & 6.03 & 15.22 \\
\hline
\end{tabular}

(b) Global consistency model

\begin{tabular}{|l|r|r|r|r|r|}
\hline Road feature & \multicolumn{1}{|c|}{ Min. } & \multicolumn{1}{c|}{ Max. } & \multicolumn{1}{c|}{ Mean } & \multicolumn{1}{c|}{ Median } & \multicolumn{1}{c|}{ St. Dev. } \\
\hline Length $(\mathrm{km})$ & 0.57 & 7.30 & 2.49 & 2.29 & 1.30 \\
\hline AADT $(\mathrm{vpd})$ & 538 & 7,700 & 2,077 & 1,417 & 1,722 \\
\hline$C C R(\mathrm{gon} / \mathrm{km})$ & 0 & 490.11 & 84.25 & 42.04 & 96.51 \\
\hline Crashes $(2012-2016)$ & 0 & 22 & 3.78 & 2 & 4.37 \\
\hline
\end{tabular}

NOTES:

Min=Minimum; Max=Maximum; St. Dev. $=$ Standard deviation; AADT=Annual Average Daily Traffic; $D D=$ Driveway

Density; $\mathrm{CCR}=$ Curvature Change Rate; na $=$ not applicable; Crashes $=$ Number of crashes with injuries

$1 \mathrm{mi}=1,609.34 \mathrm{~m}, 1 \mathrm{ft}=0.3048 \mathrm{~m}$.

$1 \mathrm{gon} / \mathrm{km}=1.448 \% \mathrm{mi}$ 
519 Table 2. Statistical summary of the CMFs.

\begin{tabular}{|c|c|c|c|c|c|c|c|c|c|}
\hline \multirow{3}{*}{ CMF } & \multirow{3}{*}{ Description } & \multicolumn{8}{|c|}{ Type of road segment } \\
\hline & & \multicolumn{4}{|c|}{ Horizontal Curves } & \multicolumn{4}{|c|}{ Tangents } \\
\hline & & Min. & Max. & Mean & St. Dev. & Min. & Max. & Mean & St. Dev. \\
\hline $\mathrm{CMF}_{1 \mathrm{r}}$ & Lane width & 1 & 1.1173 & 1.044 & 0.02789 & 1 & 1.1173 & 1.044 & 0.028 \\
\hline $\mathrm{CMF}_{2 \mathrm{r}}$ & $\begin{array}{l}\text { Shoulder width and } \\
\text { type }\end{array}$ & 1.031 & 1.1321 & 1.066 & 0.02789 & 1.024 & 1.1321 & 1.066 & 0.02821 \\
\hline $\mathrm{CMF}_{3 \mathrm{r}}$ & Horizontal curves & 1 & 10.059 & 1.795 & 1.36664 & 1 & 1 & 1 & 0 \\
\hline $\mathrm{CMF}_{4 \mathrm{r}}$ & Superelevation & 1 & 1 & 1 & 0 & 1 & 1 & 1 & 0 \\
\hline $\mathrm{CMF}_{5 \mathrm{r}}$ & Grades & 1 & 1 & 1 & 0 & 1 & 1 & 1 & 0 \\
\hline $\mathrm{CMF}_{6 \mathrm{r}}$ & Driveway density & 1 & 2.8943 & 1.271 & 0.36885 & 1 & 7.526 & 1.693 & 3.76648 \\
\hline $\mathrm{CMF}_{7 \mathrm{r}}$ & $\begin{array}{l}\text { Centerline rumble } \\
\text { strips }\end{array}$ & 1 & 1 & 1 & 0 & 1 & 1 & 1 & 0 \\
\hline $\mathrm{CMF}_{8 \mathrm{r}}$ & Passing lanes & 1 & 1 & 1 & 0 & 1 & 1 & 1 & 0 \\
\hline $\mathrm{CMF}_{9 \mathrm{r}}$ & $\begin{array}{l}\text { Two-way left-turn } \\
\text { lanes }\end{array}$ & 1 & 1 & 1 & 0 & 1 & 1 & 1 & 0 \\
\hline $\mathrm{CMF}_{10 \mathrm{r}}$ & Roadside design & 1 & 1.1429 & 1.059 & 0.07002 & 1 & 1.1429 & 1.057 & 0.06964 \\
\hline $\mathrm{CMF}_{11 \mathrm{r}}$ & Lighting & 1 & 1 & 1 & 0 & 1 & 1 & 1 & 0 \\
\hline $\mathrm{CMF}_{12 \mathrm{r}}$ & $\begin{array}{l}\text { Automated speed } \\
\text { enforcement }\end{array}$ & 1 & 1 & 1 & 0 & 1 & 1 & 1 & 0 \\
\hline
\end{tabular}


521 Table 3. Parameters of goodness of fit.

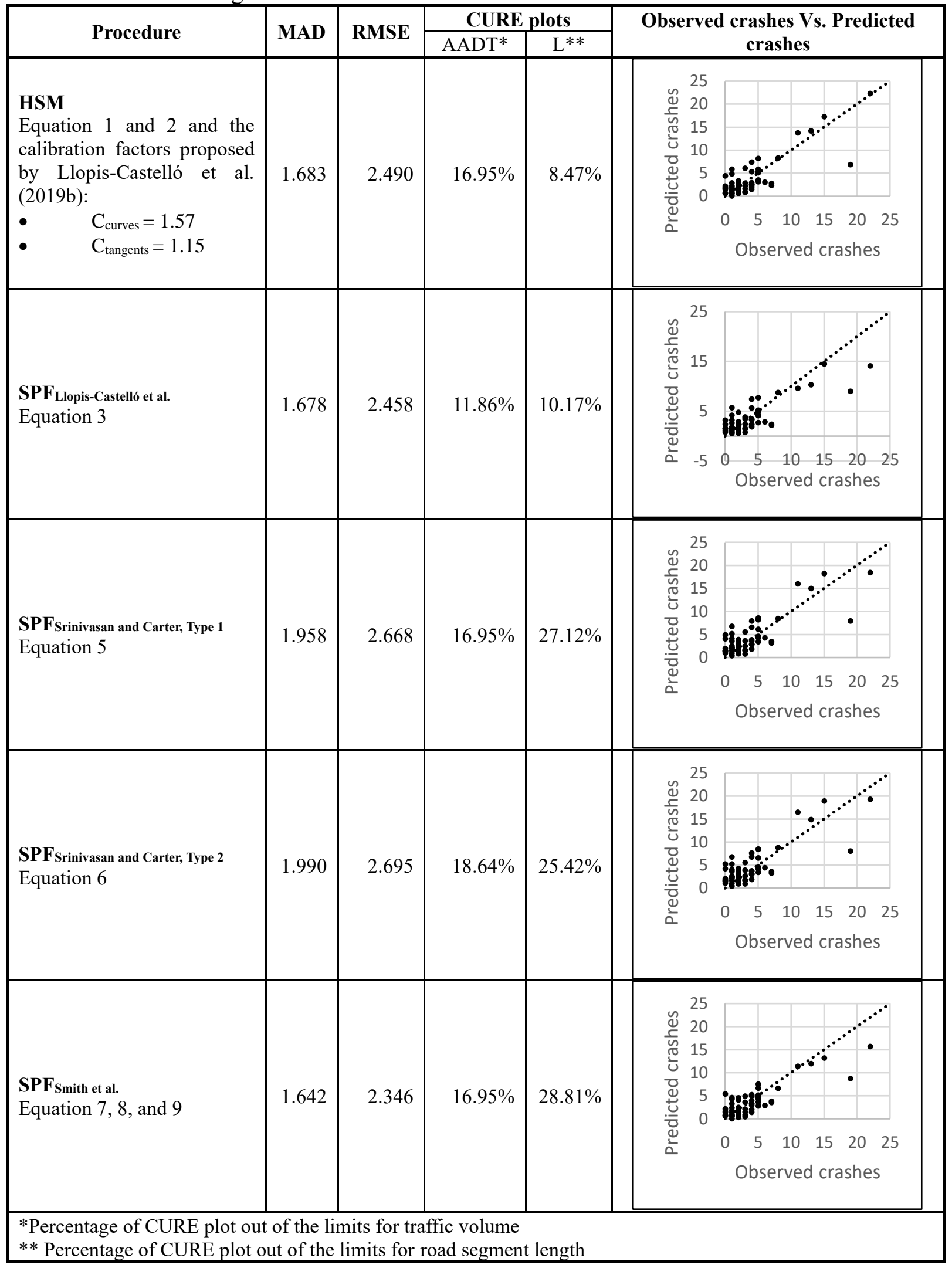




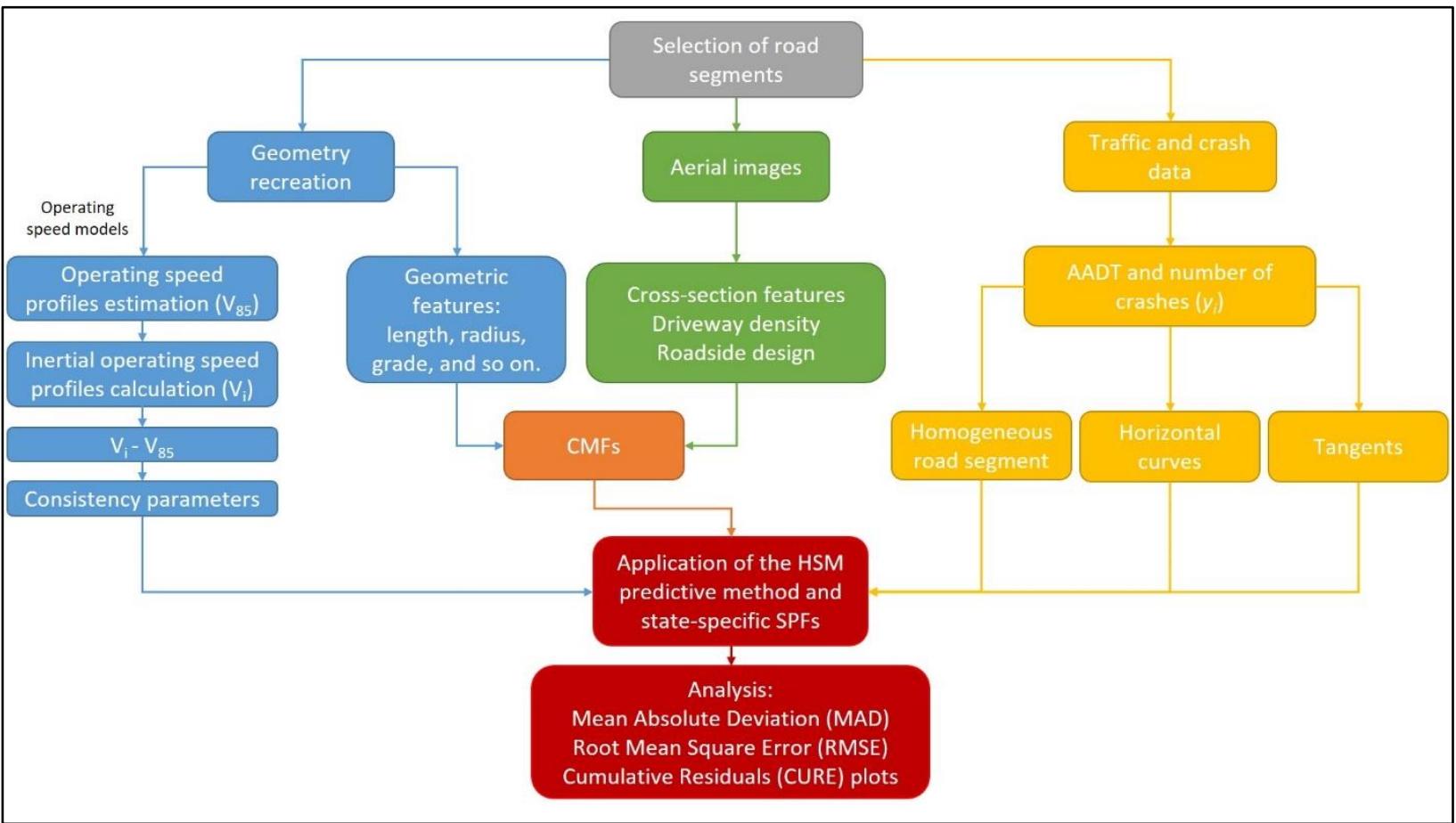

524 Figure 1. Methodology. 


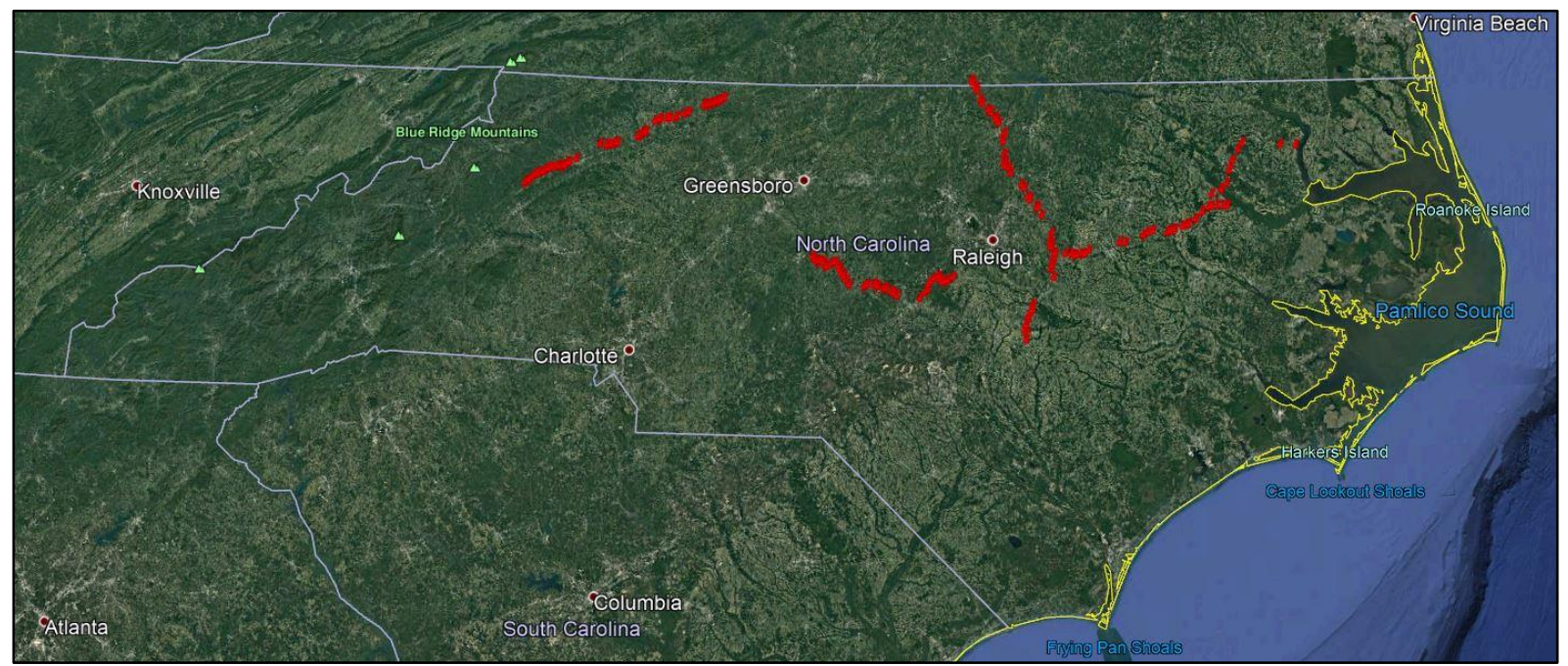

525

Figure 2. Location of the studied road segments. 


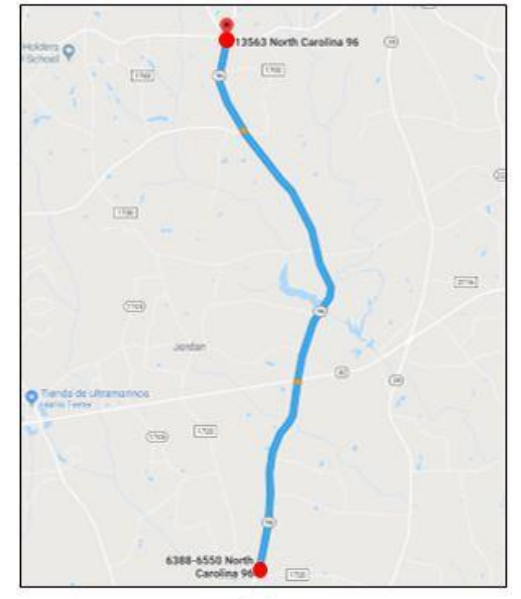

(a)

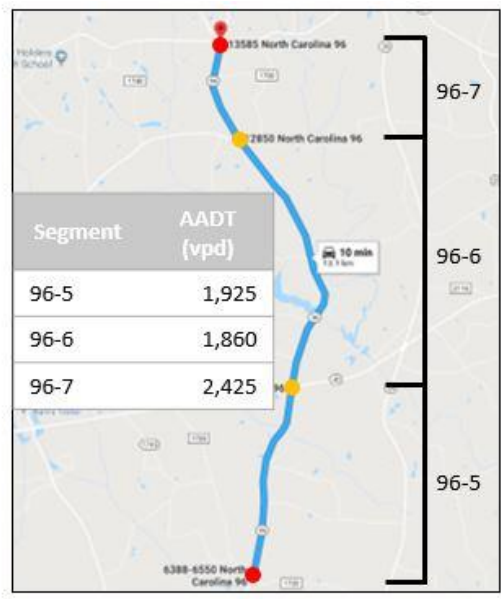

(b)

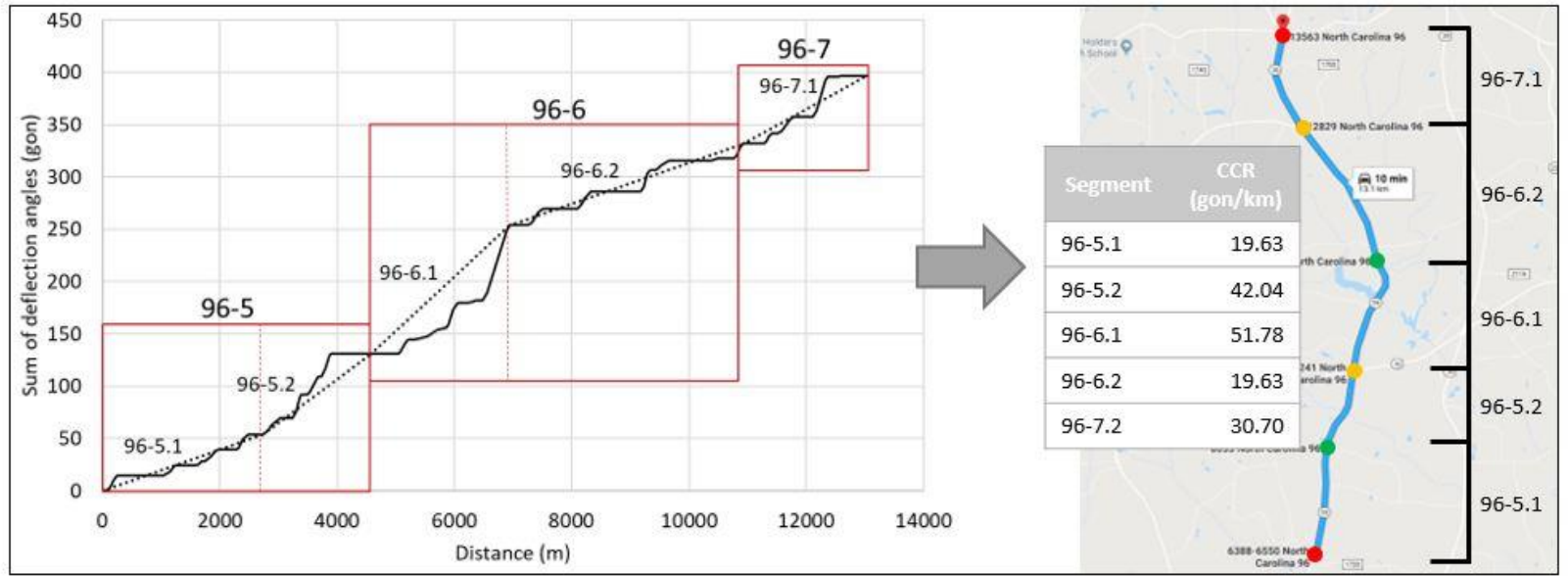

(c)

Figure 3. Road segmentation: (a) Road section; (b) Segmentation according AADT and cross529 section; (c) Segmentation according to geometric layout. 


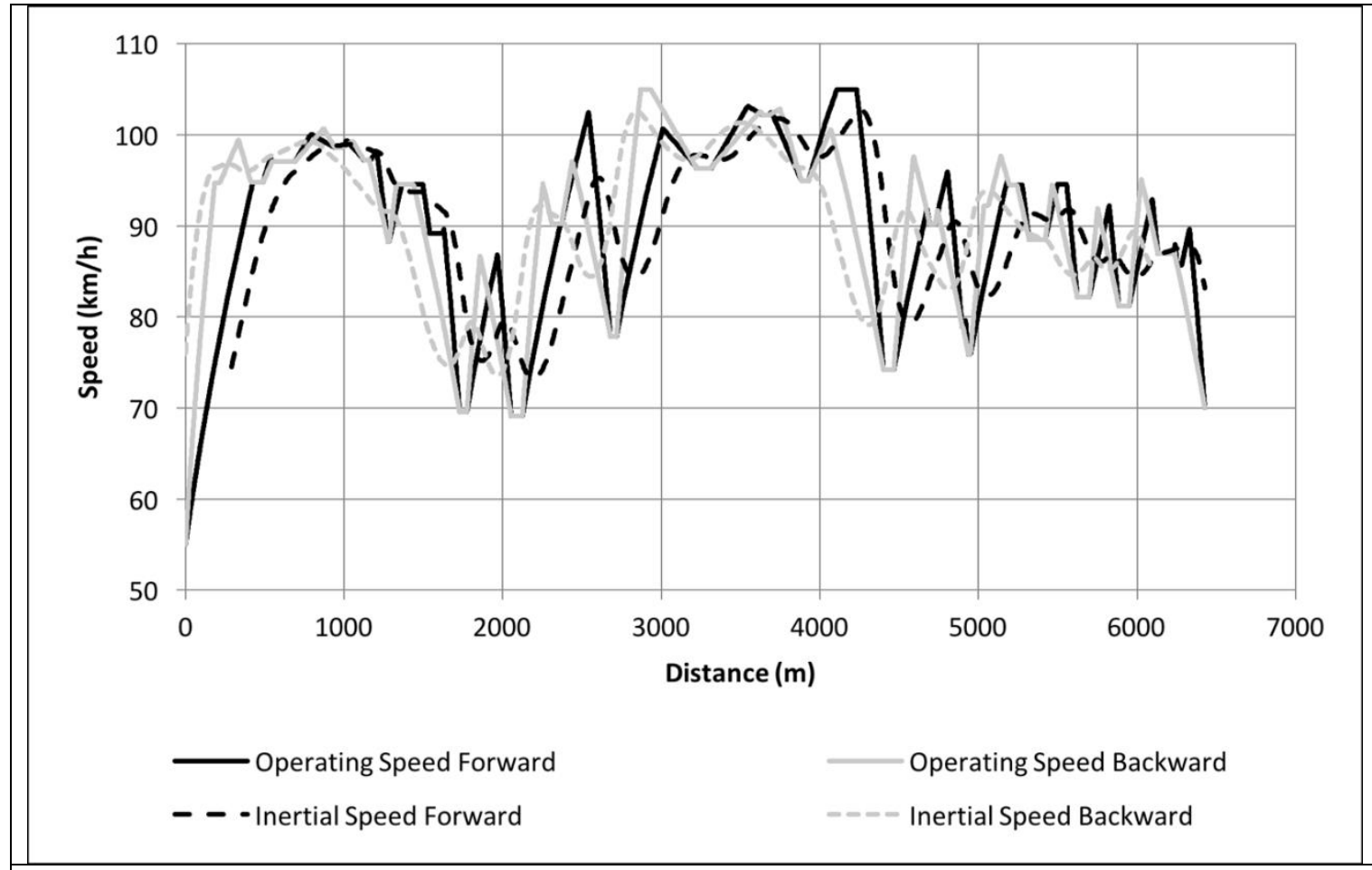

(a) Inertial operating speed profile and operating speed profile.

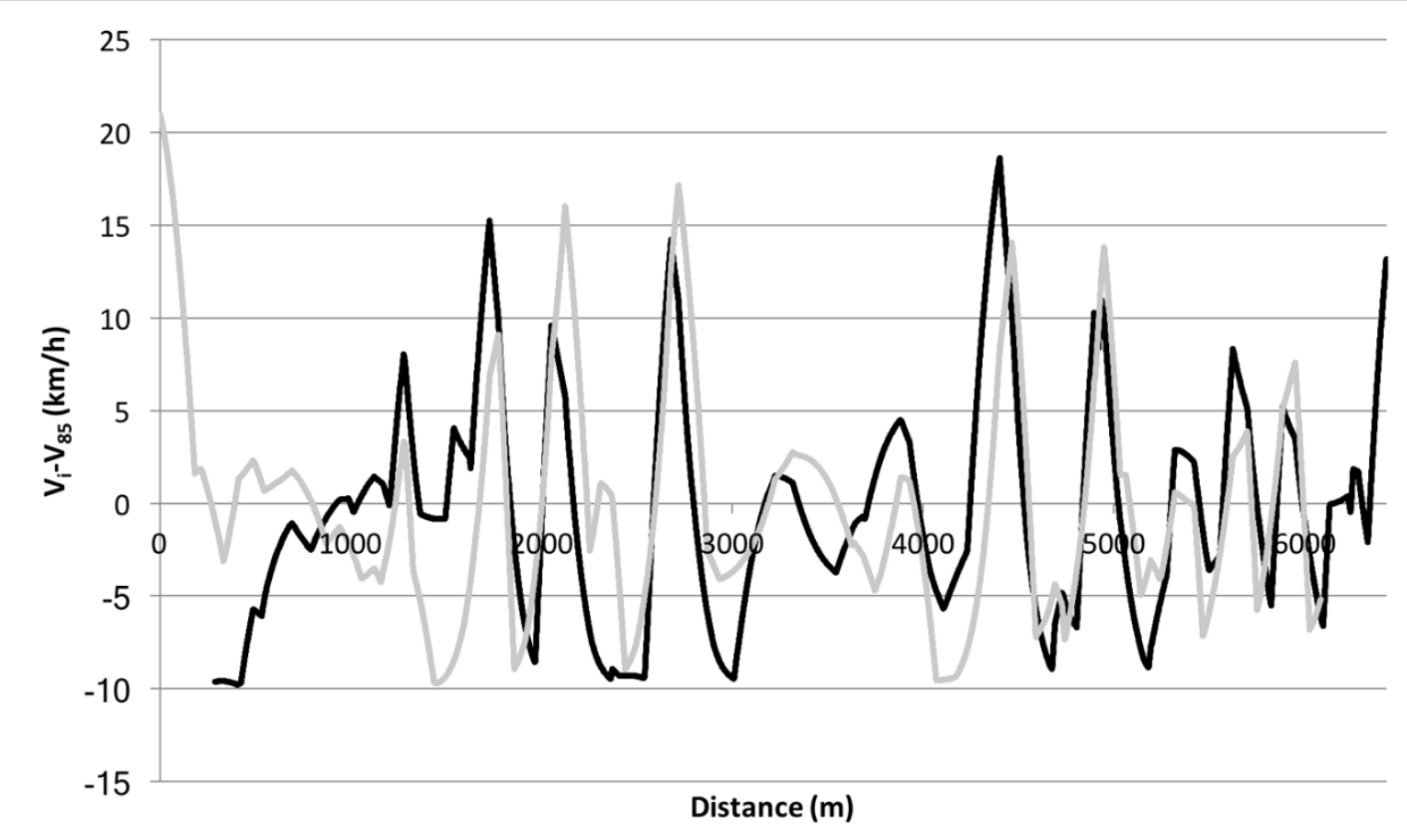

—ICl Forward —ICl Backward

(b) Difference between inertial operating speed profile $\left(V_{i}\right)$ and operating speed profile $\left(V_{85}\right)$. Figure 4. Speed profiles. 


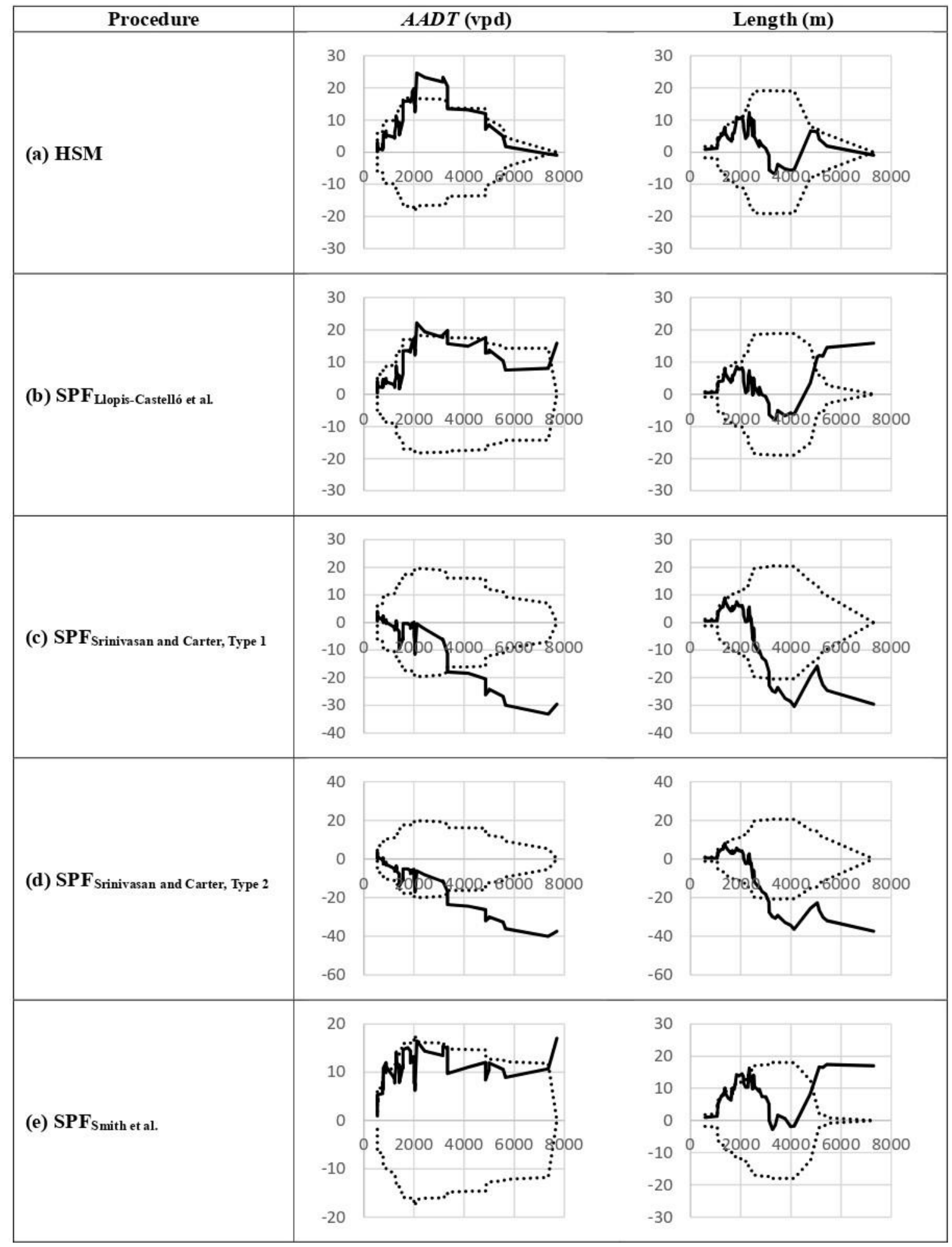




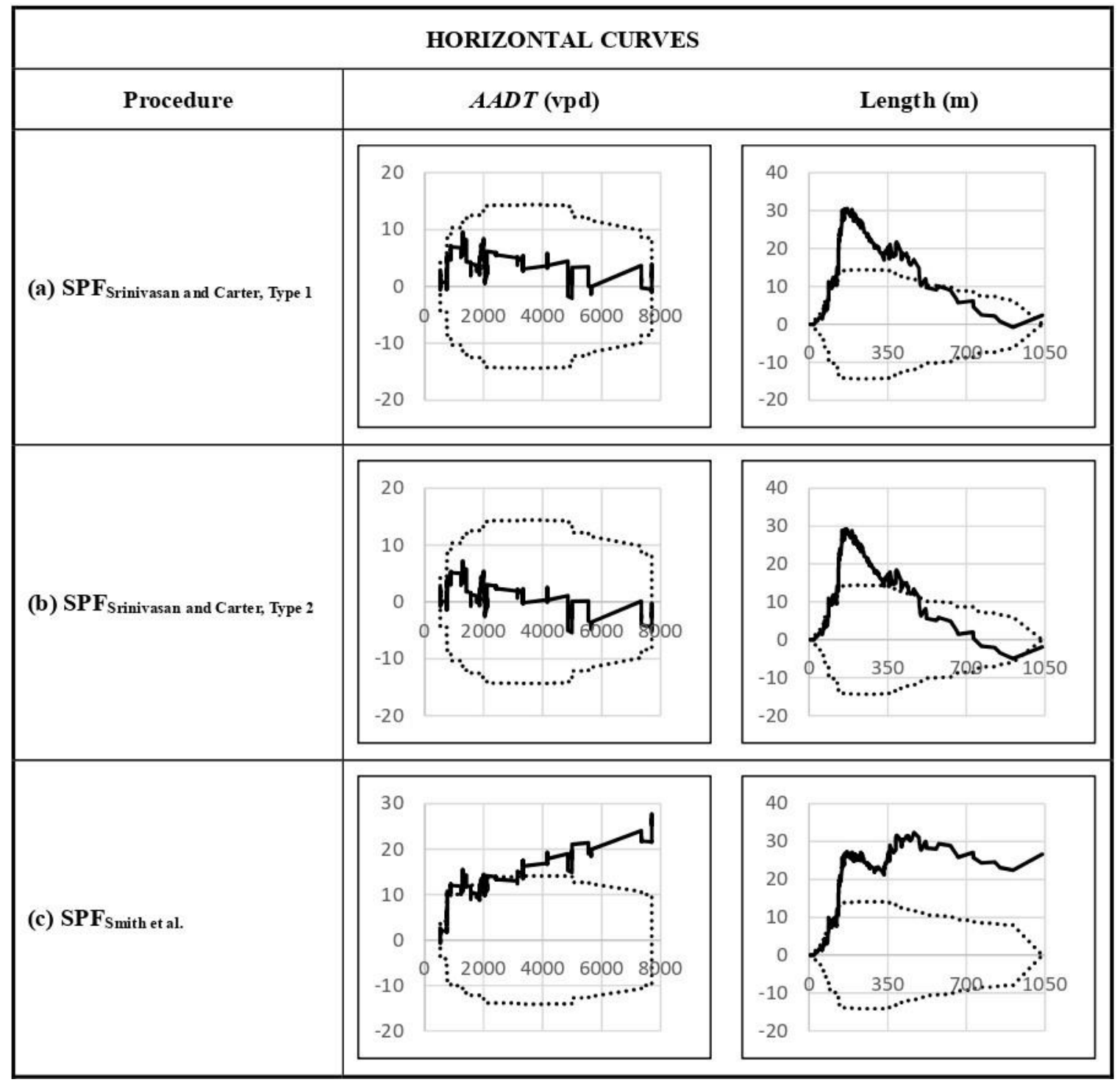

Figure 6. CURE Plots: Disaggregated analysis - Horizontal Curves. 


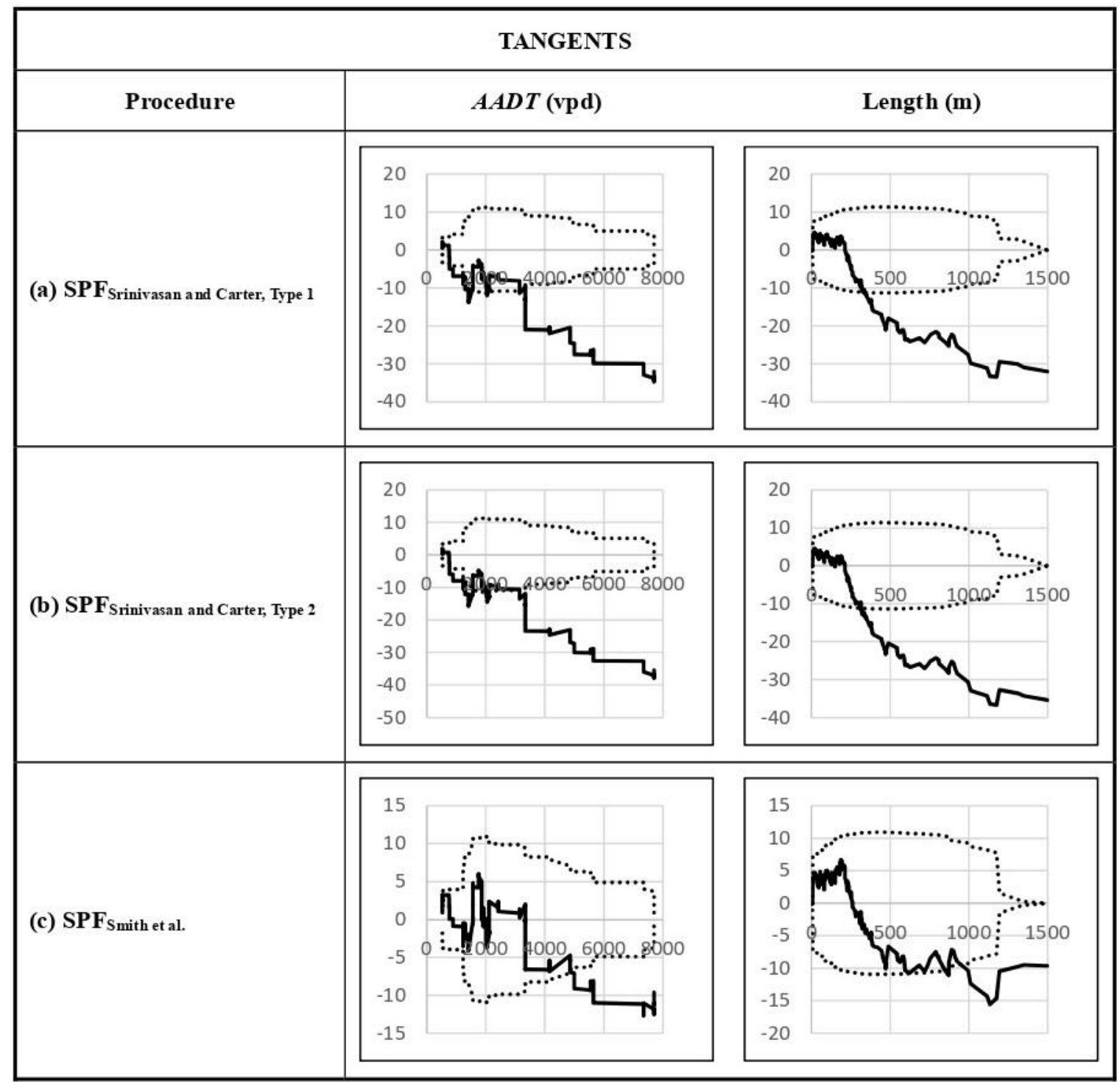




\section{$537 \quad$ Figure captions}

538 Figure 1. Methodology.

539 Figure 2. Location of the studied road segments.

540 Figure 3. Road segmentation: (a) Road section; (b) Segmentation according AADT and cross-

541 section; (c) Segmentation according to geometric layout.

$542 \quad$ Figure 4. Speed profiles.

543 Figure 5. CURE Plots.

544 Figure 6. CURE Plots: Disaggregated analysis - Horizontal Curves.

545 Figure 7. CURE Plots: Disaggregated analysis - Tangents. 